Research Article

\title{
Evaluation of levobupivacaine and bupivacaine cardiotoxicities by correlation of Brain Natriuretic Peptide protein values and arterial pressures
}

\author{
Korgün Ökmen M.D. ${ }^{1}$, Nermin Göğüş M.D. ${ }^{2}$ \\ ${ }^{1}$ University of Health Sciences, Bursa Yuksek Ihtisas Training and Research Hospital, Department of \\ Anesthesiology and Reanimation, Bursa/TURKEY \\ ${ }^{2}$ University of Health Sciences, Ankara Numune Training and Research Hospital, Department of \\ Anesthesiology and Reanimation, Ankara /TURKEY \\ Corresponding author: Korgün Ökmen (M.D.), \\ University of Health Sciences, Bursa Yuksek Ihtisas Training and Research Hospital, Department of \\ Anesthesiology and Reanimation, Mimar Sinan Quarter. Emniyet Street. 16130 Bursa/TURKEY.
}

\begin{abstract}
:
Objectives: The aim of the present study was to determine the cardiotoxic effects of the intrathecal and epidural administration of bupivacaine and levobupivacaine by investigating whether there is a correlation between the brain natriuretic peptide (BNP) protein levels and the arterial pressure.

Methods: In this prospective, randomized, double-blinded, 30 patients aged 25-70 years, who were undergo total knee arthroplasty surgery, were randomized into 2 groups. In Group $1(n=15)$ : levobupivacaine was applied and Group 2 (n = 15) bupivacaine was applied. Primary outcome measures includes BNP protein levels (at after injection 10th minute and postoperative 24th hour), systolic arterial pressure (SAP), diastolic arterial pressure (DAP), mean arterial pressure (MAP) (at preoperative, after injection 10th minute and postoperative 24th hour) was examined.

Results: In both groups, there was no statistically significant correlation between the BNP levels and the SAP, DAP and MAP value 10 minutes after the administration of combined spinal-epidural anesthesia and at the 24th hour ( $p>0.05$ )

Conclusions: We think that the cardiac effects associated with the hypotensive effects of local anesthetics cannot be revealed with the BNP. Moreover, our study results suggest that both drugs are not cardiotoxic when administered with combined epidural spinal anesthesia.
\end{abstract}

Keywords: Brain Natriuretic peptide, Cardiotoxicity, Levobupivacaine, Bupivacaine

\section{Introduction}

Regional anesthesia techniques are commonly used to perform postoperative pain management and surgical procedures (1). Local anesthetic (LA) can be used alone or in combination with opioid in peripheral nerve block techniques and in neuroaxial block applications such as spinal epidural (2). The direct cardiac side effects and the sympathetic denervationrelated indirect cardiac side effects of LA may occur, although neuroaxial block applications have positive advantages compared with general anesthesia when used for orthopedic surgical procedures (3).

The reason for considering local anesthetics to be potentially toxic for the cardiovascular system is that they can produce the effects, which they produce on the ion channels of the nerve cells (neurons), on other inducible tissues as well. $(4,5)$.

Bupivacaine, one of the most commonly used local anesthetics, is a local anesthetic, cardiac depressant characteristic of which is the most prominent. Another local anesthetic used for epidural and spinal anesthesia is Levobupivacaine. Levobupivacaine, the s (-) enantiomer of bupivacaine, is a newer drug, and although it has similar pharmacokinetic properties compared with racemic bupivacaine, the studies conducted have attempted to determine that the cardiovascular side effects of levobupivacaine were less $(6,7)$. Although some of these studies have indicated that the hemodynamic and anesthetic effects were similar with bupivacaine, some of them have suggested different arguments (6-8). Even though the studies were mostly conducted on ECG results, there are also studies determined that biochemical parameters could also be used. The brain natriuretic peptide (BNP) that can be used in the diagnosis and follow-up of possible myocardial damage is one of these biochemical parameters (9). The BNP produced by the heart is released by myocardial cells when the left 


\section{Korgün Ökmen M.D et al / Evaluation of levobupivacaine and bupivacaine cardiotoxicities by correlation of Brain Natriuretic Peptide protein values and arterial pressures}

ventricular wall tension and volume increase (9).

In the literature, we could not found a study evaluating the cardiac effects of levobupivacaine and bupivacaine with the BNP levels. In this study, we aimed to determine the cardiotoxic effects of the intrathecal and epidural administration of bupivacaine and levobupivacaine by investigating whether there is a correlation between the BNP protein levels and the arterial pressure.

\section{Material and Methods}

In our study designed as prospective, randomized, doubleblinded, 40 patients agreed to undergo total knee arthroplasty (TDP) surgery with combined spinal-epidural anesthesia were evaluated in terms of compliance after the ethics committee approval. Patients aged between 20-70 years in the risk class of ASA I-III, who agreed to participate, were included in the study. Those, who have a cardiac disease, systemic diseases such as DM, HT and infection in the lumbar region and anatomical deformities in the lumbar region and are hypersensitive to the agents to be used in the study, were excluded from the study.

Since 10 patients had exclusion criteria, 30 patients were included in the study. Detailed information about the study was provided to all patients. Written consents were obtained from all patients. After demographic characteristics and preoperative measurements of the patients were recorded, the patients were randomized into 2 groups using a random number table. Group $1(n=15)$ was designated as the levobupivacaine group and Group $2(\mathrm{n}=15)$ was designated as the bupivacaine group.

\section{Interventions:}

Preoperative Period: Patients were monitored by standard methods (noninvasive blood pressure [systolic arterial pressure (SAP), diastolic arterial pressure (DAP), mean arterial pressure (MAP) and heart rate (HR)].

Operative Period: The epidural space the patients placed in the side-lying position before the operation was reached by a $18 \mathrm{G}$ Tuohy epidural needle using the loss of resistance technique through the L3-4 or L4-5 interspaces. The subarachnoid space was reached by a $27 \mathrm{G}$ spinal needle delivered through the epidural needle, and after the observation of free CSF flow, 15 mgr (3 cc) isobaric levobupivacaine was injected for Group I and $15 \mathrm{mgr}$ ( $3 \mathrm{cc}$ ) isobaric bupivacaine was injected for Group II. Subsequently, a $20 \mathrm{G}$ epidural catheter was inserted through the spinal epidural needle into the epidural space.

The sensory block level was checked by pinprick test every 5 minutes in patients who were followed up in the supine position. When the sensory block reached T10 level (approximately $10^{\text {th }}$ minute after injection), following appropriate site sterilization, venous blood sample was taken from the antecubital vein for the measurement of BNP protein level and the surgical procedure was initiated.

The SAP, DAP, HR values were recorded at 5 minute intervals and the MAP values were estimated throughout all surgical procedures. Atropine $0.5 \mathrm{mg}$ (IV) was administered when the HR reduced below 50/min. during the surgery and ephedrine $10 \mathrm{mg}$ (IV) was administered when the MAP control value reduced below $20 \%$.

Postoperative Period: By the end-of-surgery, patient controlled analgesia (PCA) device was connected via the epidural route and a local anesthetic infusion was initiated. The PCA device settings were as follows: a basal infusion rate of $4 \mathrm{ml} / \mathrm{hour}$, a bolus dose of $2 \mathrm{ml}$, a lockout time of 30 minutes.

The dose of local anesthetic used in epidural infusion was as follows: Group I: $1.25 \mathrm{mg} / \mathrm{ml}$ levobupivacaine, Group II: 1.25 $\mathrm{mg} / \mathrm{ml}$ bupivacaine. Postoperative follow-up of the patients was performed with SAP, DAP and MAP at 0th and 1st, 6th, 12th, 24th hours. When the visual pain scores (VAS) were $>4$, diclofenac $75 \mathrm{mg}$ (IM) was administered, and the data were recorded. Following appropriate site sterilization, the venous blood sampling was performed from antecubital vein for the measurement of BNP protein level at postoperative 24th hour.

BNP: The serum BNP assays were studied in the biochemistry laboratory using the Abbott Axsym System in BNP kit with the MEIA (microparticle enzyme immunoassay) technique after separating the serum following the centrifugation at 5000 $\mathrm{rpm}$ for $10 \mathrm{~min}$. The results were given in $\mathrm{pg} / \mathrm{ml}$.

\section{Statistical Analysis}

SPSS version 22.0 statistical package program was used for the statistical analysis. Descriptive statistical methods were used in the analysis of categorical data. Whether or not the distribution was normal was assessed by the Shapiro-Wilk test. Student's t-test was used to compare whether or not there was difference between the groups, since normal distribution was found in the study. The correlation analyzes were carried out by the Pearson correlation test. Probability (P) values smaller than $\alpha=0.05$ were considered as significant and there is a difference between the groups; the values greater than $\alpha=0.05$ were considered as insignificant and there is no difference between the groups.

\section{Results:}

The study was completed with a total of 30 patients (Group I $n=15$, Group II $n=15$ ). There was no statistically significant difference between the two groups in terms of demographic characteristics ( $\mathrm{p}>0.05)$ (Table 1).

Table 1: Comparison of the demographic characteristics of the patients (Mean \pm SD)

\begin{tabular}{|c|c|c|c|}
\hline & Group I $(n=15)$ & Group II $(n=15)$ & $\mathrm{P}$ \\
\hline Age (Year) & $62.67 \pm 4.66$ & $\begin{array}{|lll|} & 61.47 & \pm \\
6.26 & & \end{array}$ & 0.845 \\
\hline Gender (M/F) & $1 / 14$ & $1 / 14$ & N/A \\
\hline BMI $\left(\mathrm{kg} / \mathrm{m}^{2}\right)$ & $30.42 \pm 3.44$ & $29.95 \pm 3.31$ & 0.705 \\
\hline
\end{tabular}

M: Male, F: Female, BMI: Body mass index 


\section{Korgün Ökmen M.D et al / Evaluation of levobupivacaine and bupivacaine cardiotoxicities by correlation of Brain Natriuretic Peptide protein values and arterial pressures}

There was no statistically significant difference between the groups in terms of systolic arterial pressures at all measurement times ( $>0.05)$ (Table 2). The inter-group comparison of diastolic arterial pressures and mean arterial pressures revealed that there was a statistically significant difference between the groups with a lower value in the bupivacaine group only during the postoperative 24th-hour measurements ( $>0.05)$ (Table 2).

Table2: Comparison of the SAP, DAP and MAP values between the groups

\begin{tabular}{|l|l|l|l|}
\hline SAP & Group I (n=15) & Group II (n=15) & $\mathrm{p}$ \\
\hline $\begin{array}{l}\text { preoperative } \\
\begin{array}{l}\text { 10th minute after } \\
\text { injection }\end{array}\end{array}$ & $161.33 \pm 26.07$ & $148.07 \pm 19.76$ & 0.127 \\
\hline $\begin{array}{l}\text { postoperative24 } \\
\text { hour }\end{array}$ & $126.00 \pm 14.24$ & $118.80 \pm 8.51$ & 0.104 \\
\hline $\begin{array}{l}\text { DAP } \\
\text { preoperative }\end{array}$ & $87.87 \pm 16.35$ & $84.67 \pm 11.65$ & 0.542 \\
\hline $\begin{array}{l}\text { 10th minute after } \\
\text { injection }\end{array}$ & $73.20 \pm 15.39$ & $74.93 \pm 10.47$ & 0.721 \\
\hline $\begin{array}{l}\text { postoperative } 24^{\text {th }} \\
\text { hour }\end{array}$ & $75.07 \pm 7.91$ & $69.15 \pm 6.62$ & $\mathbf{0 . 0 4 3}$ \\
\hline MAP & $87.93 \pm 18.52$ & $95.27 \pm 14.38$ & 0.236 \\
\hline $\begin{array}{l}\text { preoperative } \\
\text { 10th minute after } \\
\text { injection }\end{array}$ & $111.40 \pm 26.11$ & $104.60 \pm 11.93$ & 0.367 \\
\hline $\begin{array}{l}\text { postoperative } 24^{\text {th }} \\
\text { hour }\end{array}$ & $97.87 \pm 10.87$ & $90.13 \pm 8.69$ & $\mathbf{0 . 0 4 0}$ \\
\hline
\end{tabular}

SAP: systolic arterial pressure, DAP: diastolic arterial pressure, MAP: mean arterial pressure

The inter-group comparison of the BNP levels revealed that there was a statistically significant difference between the two groups ( $p$ <0.05) 10 minutes after the administration of combined spinal-epidural anesthesia with a lower value in the bupivacaine group. There was no statistically significant difference between the groups at the postoperative 24th hour (p>0.05) (Table 3).

Table3: Comparison of the BNP values between the groups

\begin{tabular}{|l|l|l|l|}
\hline \multicolumn{1}{|c|}{ BNP } & Group I (n=15) & Group II (n=15) & P \\
\hline $\begin{array}{l}\text { 10th minute after } \\
\text { injection }\end{array}$ & $61.63 \pm 40.18$ & $25.03 \pm 15.43$ & $\mathbf{0 . 0 0 3}$ \\
\hline $\begin{array}{l}\text { postoperative } \\
\text { 24th hour }\end{array}$ & $76.26 \pm 72.05$ & $45.85 \pm 51.75$ & 0.195 \\
\hline
\end{tabular}

In both groups, there was no statistically significant correlation between the BNP levels and the SAP, DAP and MAP value 10 minutes after the administration of combined spinal-epidural anesthesia and at the 24th hour $(\mathrm{p}>0.05)$ (Table 4) (Table 5).
Table 4: Correlations of BNP and SAB, DAB, MAP after spinal block 10th minute

\begin{tabular}{|c|c|c|c|c|c|c|}
\hline \multirow[b]{2}{*}{ Group 1} & \multicolumn{2}{|c|}{$\begin{array}{lr}\text { SAB } & \text { after } \\
\text { injection } & 10^{\text {th }} \\
\text { minute } & \end{array}$} & \multicolumn{2}{|c|}{$\begin{array}{lr}\text { DAB } & \text { after } \\
\text { injection } & 10^{\text {th }} \\
\text { minute } & \end{array}$} & \multicolumn{2}{|c|}{$\begin{array}{lr}\text { MAP } & \text { after } \\
\text { injection } & 10^{\text {th }} \\
\text { minute } & \end{array}$} \\
\hline & $\mathrm{R}$ & $\mathrm{p}$ & $\mathrm{R}$ & $\mathrm{p}$ & $\mathrm{R}$ & $\mathrm{p}$ \\
\hline $\begin{array}{l}\text { BNP after } \\
\text { injection } 10^{\text {th }} \\
\text { minute }\end{array}$ & 0.270 & 0.330 & 0.435 & 0.105 & 0.315 & 0.253 \\
\hline Group 2 & $\mathrm{R}$ & $\mathrm{p}$ & $\mathrm{R}$ & $\mathrm{p}$ & $\mathrm{R}$ & $\mathrm{p}$ \\
\hline $\begin{array}{l}\text { BNP after } \\
\text { injection } \\
\text { 10th minute }\end{array}$ & 0.276 & 0.320 & 0.251 & 0.367 & 0.399 & 0.141 \\
\hline
\end{tabular}

Table 5: Correlations of BNP and SAB, DAB, MAP after spinal block 24th hour

\begin{tabular}{|l|l|l|l|l|l|l|}
\hline & \multicolumn{2}{|l|}{$\begin{array}{l}\text { SAB after } \\
\text { injection 24th } \\
\text { hour }\end{array}$} & $\begin{array}{l}\text { DAB after } \\
\text { injection 24th } \\
\text { hour }\end{array}$ & $\begin{array}{l}\text { MAP } \\
\text { injection 24th } \\
\text { hour }\end{array}$ \\
\hline Group 1 & $\mathrm{R}$ & $\mathrm{p}$ & $\mathrm{R}$ & $\mathrm{p}$ & $\mathrm{R}$ & $\mathrm{p}$ \\
\hline $\begin{array}{l}\text { BNP after } \\
\text { injection 24th } \\
\text { hour }\end{array}$ & 0.218 & 0.435 & 0.430 & 0.109 & 0.415 & 0.124 \\
\hline Group 2 & $\mathrm{R}$ & $\mathrm{p}$ & $\mathrm{R}$ & $\mathrm{p}$ & $\mathrm{R}$ & $\mathrm{p}$ \\
\hline $\begin{array}{l}\text { BNP after } \\
\text { injection 24th } \\
\text { hour }\end{array}$ & 0.199 & 0.476 & 0.316 & 0.293 & 0.298 & 0.281 \\
\hline
\end{tabular}

\section{Discussion}

We used bupivacaine and levobupivacaine in CSEA at equal doses for total knee arthroplasty and postoperative analgesia. We did not find a statistically significant correlation between the BNP levels and the $\mathrm{SAB}, \mathrm{DAB}$ and $\mathrm{OAB}$ values measured at the 10th minute after the spinal block and at the postoperative 24th hour to determine the cardiotoxic effects of both drugs.

Although local anesthetics affect the membranes of the neurons, they may also affect the ion channels of the inducible tissues such as the heart in addition to these effects (10). The primary mechanism of action of bupivacaine on the heart, which is the most commonly known local anesthetic drug in terms of cardiotoxic effect, occurs on the cardiac sodium channels and voltage-gated potassium channels (10,11). On the other hand, levobupivacaine is the s (-) enantiomer of bupivacaine and has similar pharmacokinetic properties compared with bupivacaine; the studies conducted have shown that the post- spinal anesthetic effects of levobupivacaine were the same as those of bupivacaine $(7,12)$. It has been reported that the inhibitor effect of Levobupivacaine on the sodium and potassium channels was less than Bupivacaine, and therefore may be a new alternative in patients with cardiovascular disease $(11,13)$. However various studies have reported that the number of studies conducted on Levobupivacaine was limited, and that further studies were necessary $(14,15)$.

Animal studies on the cardiotoxicity of local anesthetics have 


\section{Korgün Ökmen M.D et al / Evaluation of levobupivacaine and bupivacaine cardiotoxicities by correlation of Brain Natriuretic Peptide protein values and arterial pressures}

different results in the literature. In these studies conducted on dogs, cardiotoxic effects have been investigated by intravenously administering different local anesthetics, and bupivacaine resulted in a mortality rate of $50 \%$, whereas this rate was $30 \%$ in levobupivacaine at the same dose (14). Two different studies attempting to determine the drug plasma concentrations for cardiovascular effects of local anesthetics have reported that bupivacaine and levobupivacaine produced similar levels of cardiovascular effects $(15,16)$. The studies conducted on cardiac conduction concluded that levobupivacaine was less cardiotoxic. In a study investigating the effects of local anesthetics on QRS duration, the rates of bupivakain and levobupivacaine have been found to be 1:0.4 (11). A study that has obtained similar results and was conducted on pigs has found that levobupivacaine was about $33-44 \%$ less toxic than bupivacaine (17).

The effects of local anesthetics administered intravenously on the cardiovascular system have been examined in volunteers. The study results conducted on humans also have different arguments. A study conducted by Stewart J. et al. has indicated that ropivacaine was effective at the same level with levobupivacaine in terms of toxicity, but bupivacaine was more toxic than these (18). Bardsley H. et al. have investigated the effects of levobupivacaine and bupivacaine on the PR interval and corrected QT (QTc) intervals in ECG, and found a statistically significant increase only in bupivacaine (19). Unlike these studies, Bader et al. have reported that the epidural administration of bupivacaine and levobupivacaine during cesarean section operations had no effect on the QT interval values in ECG (6).

Biochemical markers can also be used to determine the cardiovascular effects of local anesthetics. One of the natriuretic peptides released in cases of cardiac dysfunction is brain natriuretic peptide (BNP), and has been indicated to be used for the assessment of cardiac status after cardiotoxicity, cardiac and noncardiac surgery. (20-23)

Cuthbertson $\mathrm{BH}$ et al. presented an argument on that the BNP levels were important in detecting the cardiac pathologies in order to determine the risk of cardiac complications and the mortality rate following a major emergency non-cardiac surgery (24). A study conducted by Vetrugno et al. showed that the BNP measured preoperatively and postoperatively may be a precursor of important cardiac side-effect events (25).

A study conducted by Terasako et al. has investigated the ANP and BNP levels in patients underwent hip arthroplasty. As a result of their study, they argued that the indication of hypertension-related inadequate myocardial reserve could be detected by elevated ANP and BNP levels (23).

When the conducted studies were examined, there was no other study evaluating the cardiotoxic effects of different types of local anesthetic drugs with the BNP. While there was no perioperative difference between the systolic, diastolic, and mean arterial pressures recorded between the groups within the scope of our study, the diastolic arterial pressures and the mean arterial pressures at the postoperative 24th hour were statistically significantly lower in the bupivacaine group. The results of the perioperative hemodynamic parameters seemed to be similar to those of the studies in the literature in which intrathecal drug was administered $(12,26)$. However, despite the lower DAP and MAP values in the bupivacaine group at the postoperative 24th hour, there was no statistically significant difference in the BNP levels at this hour between the groups and similarly, there was no statistically significant correlation.

Limitation: We consider the small number of patients and not comparing the BNP levels with the ECG findings as the limitations of our study.

\section{Conclusions:}

It is interesting to note as a result of this study that although the effects of levobupivacaine and bupivacaine administered in combination with epidural spinal anesthesia on the postoperative 24th hour BNP values were similar, the postoperative 24th hours DAP and MAP values were lower in the bupivacaine group, however there was no correlation with BNP. Therefore, we think that the cardiac effects associated with the hypotensive effects of local anesthetics cannot be revealed with the BNP. Moreover, our study results suggest that both drugs are not cardiotoxic when administered with combined epidural spinal anesthesia.

\section{Conflict of Interest: None.}

Financial disclosure: The authors have no financing to disclose.

Informed consent: Informed consent was obtained from all individual participants included in the study.

Ethical approval: "All procedures performed in studies involving human participants were in accordance with the ethical standards of the institutional and/or national research committee and with the 1964 Helsinki declaration and its later amendments or comparable ethical standards."

\section{References}

[1] Erdine S, Özyalçın SN, Raj PP, et al. Rejyonal Anestezi. İstanbul: Nobel Tip Kitabevleri;2005; p.185-91.

[2] Rawal N, Holmstrom B, Crowhurst JA, Van Zundert A. The combined spinal- epidural technique anesthesiology. Anesthesiol Clin North America. 2000; 18: 267-95.

[3] Collins JV. Principles of Anaesthesiology. Third Edition. Philadelphia Lea and Febiger; 1993; p.1445-97.

[4] Chester C, Bleckner LL. Anaesthetic agents for advanced regional anaesthesia. Drug. 2005; 65: 745-59.

[5] Kayhan Z. Klinik Anestezi. 2. Bask1. İstanbul Logos Yayınc1lık; 2004; p. 503-23.

[6] Bader AM, Tsen LC, Camann WR, Nephew E, Datta S. CIinical effects and maternal and fetal plasma concentrations of $\% 0,5$ epidural levobupivacaine versus 


\section{Korgün Ökmen M.D et al / Evaluation of levobupivacaine and bupivacaine cardiotoxicities by correlation of Brain Natriuretic Peptide protein values and arterial pressures}

bupivacaine for cesarean delivery. Anesthesiology. 1999; 90: 1596-601.

[7] Casati A, Moizo E, Marchetti C, Vinciguerra F. A prospective, randomized, double-blind comparison of unilateral spinal anesthesia with hyperbaric bupivacaine, ropivacaine, or levobupivacaine for inguinal herniorrhaphy. Anesth Analg. 2004; 99:1387-92.

[8] Cuvas O, Er AE, Ongen E, Basar H. Spinal anesthesia for transurethral resection operations: bupivacaine versus levobupivacaine. Minerva Anestesiol. 2008;74:697-701.

[9] Suttner SW, Boldt J. Natriuretic peptide system: physiology and clinical utility. Curr Opin Crit Care. 2004;10: 336-41.

[10] Kawano T, Oshita S, Takahashi A, et al. Molecular mechanisms of the inhibitory effects of bupivacaine, levobupivacaine, and ropivacaine on sarcolemmal adenosine triphosphate-sensitive potassium channels in the cardiovascular system. Anesthesiology. 2004; 101: $390-8$

[11] Mazoit JX, Decaux A, Bouaziz H, Eduard A. Comparative ventricular electrophysiologic effect of rasemic bupivacaine, levobupivacaine and ropivacaine on the isolated rabbit heart. Anesthesiology 2000; 93: 78492.

[12] Fatorini F, Ricci Z, Rocco A, et al. Levobupivacaine versus racemic bupivacaine for spinal anaesthesia in orthopaedic major surgery. Minerva Anesttesiol. 2006; 72: 637-44.

[13] Mather LE, Chang DH. Cardiotoxicity with modern local anaesthetics: is there a safer choice? Drugs. 2001; 61(3): 333-342.

[14] Groban L, Deal DD, Vernon JC, James R L, Butterworth J. Cardiac resuscitation after incremental overdosage with lidocaine, bupivacaine, levobupivacaine, and ropivacaine in anesthetized dogs. Anesth Analg. 2001; 92: 37-43.

[15] Groban L, Deal DD, Vernon JC, James RL, Butterworth J. Ventricular arrhythmias with or without programmed electrical stimulation after incremental overdosage with lidocaine, bupivacaine, levobupivacaine, and ropivacaine. Anesth Analg. 2000; 91: 1103-11.

[16] Ohmura S, Kawada M, Ohta T, Kobayashi T. Systemic toxicity and resuscitation in bupivacaine, levobupivacaine or ropivacaine infused rats. Anesth Analg 2001; 93: 7438 .

[17] Morrison SG, Dominguez JJ, Frascarolo P, Reiz S. A comparison of the electrocardiographic cardiotoxic effects of racemic bupivacaine, levobupivacaine, and ropivacaine in anesthetized swine. Anesth Analg. 2000 Jun;90(6):1308-14.

[18] Stewart J, Kellett N, Castro D. The central nervous system and cardiovascular effects of levobupivacaine and ropivacaine in healthy volunteers. Anesth Analg. 2003;97: 4126.

[19] Bardsley H, Griswood R, Baker H, Nimmo W. A comparison of the cardiovasculer effects of levobupivacaine and rac-bupivakaine following intravenous administration to healty volunteers. Br J Clin Pharmacol 1998; 46: 245-9.

[20] Pongprot Y, Sittiwangkul R, Charoenkwan P, Silvilairat S. Use of Cardiac Markers for Monitoring of Doxorubixin-induced Cardiotoxicity in Children With Cancer. Journal of Pediatric Hematology/Oncology. 2012; 34: 589-95.

[21] Karakılıç E, M Ali Karaca, Bozkurt Ş, Coşkun F, Sivri B. BNP Nedir? Acil Serviste Beyin Natriüretik Faktör (BNP) Kullanımı. Akademik Acil Tıp dergisi. 2005; 3: 7-10.

[22] Mahla E, Baumann A, Rehak P, et al. N-terminal probrain natriuretic peptide identifies patients at high risk for adverse cardiac outcome after vascular surgery. Anesthesiology. 2007; 106:1088-95.

[23] Terasako K. Perioperative plasma concentrations of atrial and brain natriuretic peptides in patients undergoing hip arthroplasty. Anaesth Intensive Care. 2002; 30: 588-90.

[24] Cuthbertson BH, Card G, Croal BL, McNeilly J, Hillis GS. The utility of B-type natriuretic peptide in predicting postoperative cardiac events and mortality in patients undergoing major emergency non-cardiac surgery. Anaesthesia. 2007; 62: 875-81.

[25] Vetrugno L, Langian N, Gisonni R, et al. Prediction of early postoperative major cardiac events after elective orthopedic surgery: the role of B-type natriuretic peptide, the revised cardiac risk index, and ASA class. BMC Anesthesiology. 2014; 14: 20.

[26] Burke D, Kennedy S, Bannister J. Spinal anesthesia with $0.5 \%$ S(-) bupivacaine for elektive lower limb surgery. Reg Anesth Pain Med 1999;24:519-23. 